\title{
Genetic Variations in Attention Deficit Hyperactivity Disorder Subtypes and Treatment Resistant Cases
}

\author{
Dilek Unal $^{1}$, Mehmet Fatih Unal' ${ }^{1}$, Mehmet Alikasifoglư ${ }^{2}$, and Arda Cetinkaya ${ }^{2}$ \\ ${ }^{1}$ Department of Child and Adolescent Psychiatry, Hacettepe University School of Medicine, Ankara, Turkey \\ ${ }^{2}$ Department of Medical Genetics, Hacettepe University School of Medicine, Ankara, Turkey
}

Objective We evaluated the distribution of alpha-2A adrenergic receptor (ADRA2A) and catechol-o-methyltransferase (COMT) single nucleotide polymorphisms (SNPs) among ADHD subtypes and other homogeneous patient populations including treatment-resistant cases and patients with high symptom severity.

Methods 121 ADHD patients aged 6-18 years were included in the study. Diagnosis and subtypes designation were confirmed using the Kiddie Schedule for Affective Disorders and Schizophrenia (K-SADS) and symptoms were evaluated using the Conners' Parent (CPRS) and Teacher Rating Scales (CTRS). The response to methylphenidate was assessed objectively using the Clinical Global Impression-Severity Scale (CGI-S) and Global Assessment of Functioning Scale (GAS) as well as the Continuous Performance (CPT) and Trail Making tests (TMT-A, B). Patients were genotyped for ADRA2A (rs1800544) and COMT (rs4680) SNPs by PCR/RFLP and compared to a gender-matched control group.

Results Although there was no association of COMT (rs4680) SNP with symptoms or diagnosis, the ADRA2A polymorphism, low socioeconomic status (SES), and comorbid psychiatric diagnosis were all associated with poor response to methylphenidate in logistic regression analysis.

Conclusion Clinicians may consider adjuvant strategies when these negative factors are present to increase the success of tailored ADHD treatments in the future.

Psychiatry Investig 2016;13(4):427-433

Key Words ADHD, ADRA2A, COMT, Genetics, Phenotype.

\section{INTRODUCTION}

Attention deficit hyperactivity disorder (ADHD) is a prevalent childhood-onset disorder characterized by pervasive and impairing symptoms of inattention, hyperactivity and impulsivity. According to the symptomatic phenomenology, children with $\mathrm{ADHD}$ are diagnosed as predominantly inattentive type (ADHD-IA), predominantly hyperactive/impulsive type (ADHD-HI), or combined type (ADHD-C) (DSM-IV). Although ADHD is considered as a major public health problem with a worldwide pooled prevalence of $5.29 \%$, the etiolo-

Received: September 20, 2015 Revised: December 26, 2015

Accepted: December 30, 2015 Available online: January 29, 2016

$\triangle$ Correspondence: Dilek Unal, MD

Department of Child and Adolescent Psychiatry, Hacettepe University School of Medicine, Ankara 06100, Turkey

Tel: +90-312-305-1150, Fax: +90-312-3091430

E-mail: dilekunal.beu@gmail.com

(a) This is an Open Access article distributed under the terms of the Creative Commons Attribution Non-Commercial License (http://creativecommons.org/licenses/bync/3.0) which permits unrestricted non-commercial use, distribution, and reproduction in any medium, provided the original work is properly cited. gy of ADHD remains poorly understood. ${ }^{1} \mathrm{ADHD}$ is a highly heritable developmental disorder caused by the interaction of both environmental and genetic factors that result in the interruption of neural growth process. ${ }^{2}$ Despite the important role of environmental factors in the etiology of ADHD, evidence from classical genetic studies has revealed a strong genetic component to ADHD development. The risk of ADHD among parents whose children have ADHD is 2 to 8 times higher than the general population incidence. A meta-analysis of 20 pooled twin studies indicated an estimated average heritability of $76 \%$, suggesting that ADHD has a strong genetic component. ${ }^{3}$ Methylphenidate is an effective treatment for ADHD symptoms, and recent studies evaluating the genetic risk factors associated with ADHD have focused on genes that regulate dopamine and noradrenaline neurotransmission. ${ }^{4}$ However, the heterogeneous nature of ADHD symptoms led the authors to propose that ADHD subtypes may be distinguished from each other by treatment response and genetic etiology. 5 Two polymorphisms of interest are rs4680, found in the COMT gene, and rs1800544, which is found in 
the ADRA2A gene.

The COMT enzyme catalyzes the transfer of methyl groups in the catabolism of catecholamines. A functional SNP at codon 158 of COMT (rs4680) results in a single amino acid change (methionine for valine) that significantly alters enzyme activity. ${ }^{6} \mathrm{Val} / \mathrm{Val}$ genotype at this SNP was shown to impair pre-frontal cognitive functions. ${ }^{7}$ However, the results of many COMT polymorphism studies are controversial. While a higher incidence of $\mathrm{Val} / \mathrm{Val}$ was found in children with ADHD who exhibited better treatment responses, ${ }^{8}$ in other population studies ${ }^{9-12}$ as well as in a recent meta-analysis, ${ }^{13}$ no association was found between COMT genotype and ADHD diagnosis or symptom severity.

It has been suggested that methylphenidate improves attention by stimulating the alpha2-adrenergic receptors present in dopamine-containing neurons. ${ }^{14-16}$ The 1252 G-to-C SNP, which results in an MspI site (also known as C-1291G) (rs1800544) in the promoter region of ADRA2A and a A-to-G polymorphism in the 3' untranslated region (3'-UTR) known as the DraI site (rs553668), are the two major polymorphisms that have been investigated in ADHD patients. To date, major pharmacogenetic studies have evaluated the role of the rs1800544 in the ADRA2A promoter region and some have associated the G allele with improved MPH response. ${ }^{17,18}$ Furthermore, inattention symptoms are associated with rs $1800544 .^{19,20}$

Given the results of prior research into the genetics of $\mathrm{ADHD}$, the role of COMT and ADRA2A polymorphisms remains uncertain. In this naturalistic study, we evaluated the relationship of the ADRA2A rs1800544 and COMT rs4680 SNPs with ADHD subtypes and specific clinical characteristics of $\mathrm{ADHD}$, including highly homogenous patient populations such as treatment-resistant patients and patients with increased psychiatric symptom severity. We hypothesized that rs1800544 would be more common in ADHD-IA and rs4680 would be more prevalent in the ADHD-C subtype. We also evaluated the relationship between rs4680 and high symptom severity, reduced response to treatment, low SES, impaired familial functionality, low clinical functionality, and increased psychiatric comorbidity incidence.

\section{METHODS}

\section{Patients}

121 ADHD patients aged 6-18 years were recruited from the Hacettepe University Child and Adolescent Psychiatry Department. All study participants met the DSM-IV ADHD diagnostic criteria based on clinical assessment. The patients included in the study were stimulant naive and did not receive concurrent psychotropic medications. Diagnosis and ADHD subtype were confirmed using the K-SADS. ${ }^{21}$ Children having comorbid disorders such as mental retardation, anxiety disorders, mood disorders, autism spectrum disorders, psychosis, substance use disorders as well as chronic and neurological diseases were excluded, while patients with comorbid oppositional defiant disorder, conduct disorder, and learning disorder were included. The Wechsler Intelligence Scales for Children (WISC-R or WISC-4) were applied to identify cases of mental retardation. ${ }^{22,23}$ Patients with an IQ below 70 according to the WISC-R and below 70 on the perceptual reasoning or verbal comprehension portion of the WISC-4 were excluded from the study group. The diagnosis of Learning Disorder was made using the Learning Disorder Battery to supplement clinical assessment. ${ }^{24}$ Patients were treated in our clinic with methylphenidate according to commonly accepted regimens. ${ }^{25}$ The dose range of methylphenidate was $0.7-1.1 \mathrm{mg} / \mathrm{kg}$ per day and doses were augmented during follow-up until no further clinical improvement was detected or until there were limiting adverse effects. Our study was approved by the local Ethics Committee and conducted in accordance with the Declaration of Helsinki. All patients and parents provided written informed consent. The control group was composed of 102 banked DNA samples stored in the Hacettepe University, Medical Genetics Department from a population with a similar gender distribution.

\section{Clinical assesment}

The sociodemographic, developmental and clinical features were assessed for each patient during a parent interview carried out by a child and adolescent psychiatrist at baseline. SES was classified in 5 levels according to the HollingsheadRedich Scale (level 1-2 representing low, 3 representing middle and 4-5 representing high SES). The ADHD symptoms were evaluated by the CPRS and CTRS. ${ }^{26}$ The clinician-rated CGI-S was used to assess the severity of symptoms (scoring from 1 to 7 points, 7 for the most severe) and patients who scored 3 or greater were classified as the high symptom severity group. The GAS was used to asses functionality (scoring from 0 to 100, 100 representing the most functional) and patients who scored below 60 points were categorized as the low functionality group. TMT A and $\mathrm{B}^{27}$ and Conners' $\mathrm{CPT}^{28}$ were used to assess neuropsychological deficits in the patient group. In all patients, peripheral venous blood was collected to determine genotype at the ADRA2A and COMT SNPs at the Hacettepe University, Medical Genetics Department. As ADHD is a highly heritable disorder, the parents' ADHD symptoms were evaluated using the Wender Utah Rating Scale. ${ }^{29}$ Familial functionality was assessed using the McMaster Familial Assessment Scale. ${ }^{30}$

Four-to-six weeks after initiation of methylphenidate treat- 
ment, the patients underwent the same naturalistic assessment procedure to evaluate the treatment response, which included the reapplication of the CPRS, CTRS, CGI-S, GAS, CPT and TMT A and B. 13 of 121 patients did not comply with the drug treatment and withdrew from the study prior to the treatment response assessment. Treatment responders were defined as follows: patients registering 2 points or greater improvement on the CGI-S ${ }^{31}$ and a total GAS score of 60 points or greater, corresponding to a minimum of $50 \%$ improvement on any of the sub-scales of CPRS/CTRS, ${ }^{32}$ or improvement in one of the neuropsychological tests ${ }^{33}$ applied at follow-up.

\section{Genotyping}

\section{Detection of rs1800544 in ADRA2A and rs4680 in COMT}

Genomic DNA was isolated by salt precipitation from peripheral blood leukocytes of 121 participants with ADHD and 102 gender-matched controls. ADRA2A-F (5'-TCACAC CGGAGGTTACTTCCCTCG-3'), ADRA2A-R (5'-TCCGA CGACAGCGCGAGTT-3') and COMT-F (5'-ACTGTGGC TACTCAGCTGTG-3'), COMT-R (5'-CCTTTTTCCAGG TCTGACAA-3') primer pairs were used for PCR amplification of DNA segments flanking rs1800544 and rs4680, respectively. Restriction enzyme digestion was carried out using MspI and Hsp92II (New England Biolabs, MA, USA) to genotype DNA samples for the rs1800544 variation in $A D R A 2 A$ and rs4680 variation in COMT, respectively, using a protocol modified from previous studies. ${ }^{34,35}$ Allele designations for ADRA2A and COMT are according to the NCBI reference sequences and the dbSNP database (NM_000681.3 and NM_001135162.1, respectively) (http://www.ncbi.nlm. nih.gov, www.dbsnp.com).

\section{Statistical analysis}

All statistical analyses were performed using SPSS (version 21.0). The Shapiro-Wilk test was used to assess the adherence to the normal distribution assumption. Homogeneity of variance among the groups was tested using Levene's test. Differences in numeric variables were evaluated using a Student's ttest for independent samples. The Mann-Whitney $U$ test was performed when the parametric test hypothesis was not supported, indicating the presence of a non-normal distribution. The Kruskal-Wallis test was used for the comparison of numeric variables among more than two groups. Differences in numeric variables before and after treatment were evaluated using the Wilcoxon test for dependent samples. Between group comparisons involving categorical data were carried out using either the $\chi^{2}$ test or Fisher's exact test. Differences in categoric variables before and after treatment were assessed using the McNemar test. Factors associated with treatment out- come were evaluated using multiple logistic regression analysis. Results were considered statistically significant when $\mathrm{p}<0.05$.

\section{RESULTS}

\section{Demographic data}

The sociodemographic and clinical characteristics of our sample are summarized in Table 1.

\section{Clinical data}

In this naturalistic study, mean methylphenidate dosage was $0.7 \mathrm{mg} / \mathrm{kg} /$ day. $9.1 \%$ of the patients used short acting methylphenidate and $80.2 \%$ used long acting methylphenidate.

In the first assessment, all CPRS and CTRS sub-scale scores were increased among patients with the combined ADHD subtype compared to patients with the predominantly inattentive subtype. After treatment, there was a significant decrease in CGI-S and improvement in GAS scores $(\mathrm{p}<0.05)$. In addition, the CPRS and CTRS sub-scale scores were significantly decreased at the second evaluation $(\mathrm{p}<0.05)$, with the exception of the psychosomatic sub-scale score. However, there was no significant relationship between improvement on any of the CPRS/CTRS sub-scales and DSM-IV subtype. In the neuropsychological tests, TMT A and B completion time as well as the number of errors and corrections that occurred during these tests were significantly decreased after treatment $(\mathrm{p}<0.05)$. The CPT latency period was decreased and omission/ commission error rates decreased after treatment $(\mathrm{p}<0.05)$.

Genotype frequencies did not differ between the study and the control groups (Table 2). There was no evidence for any relationship between rs4680 and ADHD subtype, symptom severity, global functionality, familial functionality, SES, or treatment response. The distribution of genotypes in patient group according to ADHD subtypes and treatment response is shown in Table 3 and 4, respectively. While COMT genotypes were not associated with any of the CPRS/CTRS subscales, GC and GG alleles for the rs1800544 polymorphism were associated with the learning problems CPRS sub-scale and the CTRS attention deficiency sub-scale $(\mathrm{p}<0.05)$. In addition, there was no difference in the distribution of COMT genotypes according to psychiatric co-morbidities.

\section{Treatment response data}

Among the 108 patients that had been assessed for treatment response, $66.6 \%$ responded to the treatment, while $33.3 \%$ did not. ADHD subtype was not associated with differences in treatment response. We used multiple logistic regression analysis to examine the relationship between various clinical parameters and treatment response. ADHD subtype, COMT genotypes, ADRA2A genotypes, low SES, presence of 
comorbid psychiatric disorder, presence of prenatal-natalpostnatal problems, presence of medical comorbidity, low parental education level, overcrowded house and age met the

Table 1. Demographic and clinical characteristics of the sample

\begin{tabular}{|c|c|c|}
\hline & \multicolumn{2}{|c|}{$\operatorname{ADHD}(\mathrm{N}=121)$} \\
\hline & Mean & SD \\
\hline Age, $y$ & 9.9 & 2.5 \\
\hline Birth weight, grams & 3163.1 & 586.7 \\
\hline \multirow[t]{2}{*}{ Pregnancy period, w } & 37.2 & 3 \\
\hline & $\mathrm{N}$ & $\%$ \\
\hline Prenatal problem & 32 & 26.4 \\
\hline Natal problem & 14 & 11.6 \\
\hline Postnatal problem & 25 & 20.7 \\
\hline Male sex & 88 & 72.7 \\
\hline \multicolumn{3}{|l|}{ Socioeconomic status } \\
\hline 1 & 3 & 2.5 \\
\hline 2 & 25 & 20.7 \\
\hline 3 & 59 & 48.8 \\
\hline 4 & 23 & 19 \\
\hline 5 & 11 & 9.1 \\
\hline $\begin{array}{l}\text { Intermarriage among parents } \\
\text { (2nd and 3rd degree) }\end{array}$ & 18 & 14.9 \\
\hline \multicolumn{3}{|l|}{ Family structure } \\
\hline Nuclear & 104 & 86 \\
\hline Extended & 10 & 8.3 \\
\hline Fragmented & 7 & 5.8 \\
\hline \multicolumn{3}{|l|}{ ADHD subtype } \\
\hline Combined & 96 & 79.3 \\
\hline Inattentive & 25 & 20.7 \\
\hline Comorbid psychiatric disorders & 65 & 53.7 \\
\hline Oppositional Defiant Disorder & 48 & 39.6 \\
\hline Conduct Disorder & 4 & 3.3 \\
\hline Specific Learning Disorder & 25 & 20.7 \\
\hline Enuresis nocturna & 16 & 13.1 \\
\hline Encoprezis & 9 & 7.3 \\
\hline Medical comorbidity & 27 & 22.3 \\
\hline $\begin{array}{l}\text { Diagnosed psychiatric disease in family } \\
\text { history }\end{array}$ & 76 & 62.8 \\
\hline \multicolumn{3}{|l|}{$\begin{array}{l}\text { Parents who had ADHD symptoms } \\
\text { at that time and/or in the past }\end{array}$} \\
\hline Fathers & 107 & 88.4 \\
\hline Mothers & 92 & 76 \\
\hline Familial functionality impaired & 112 & 92.6 \\
\hline Parental low education & 0 & 0 \\
\hline Overcrowded house & 39 & 32.2 \\
\hline Mother $<18 y$ at child birth & 2 & 1.7 \\
\hline Single-parent family & 8 & 6.6 \\
\hline Nondesired pregnancy & 20 & 16.5 \\
\hline
\end{tabular}

ADHD: attention deficit hyperactivity disorder criteria for inclusion in the multivariate analysis $(\mathrm{p}<0.25)$. The results indicated that ADRA2A GG genotype ( $\mathrm{OR}=5.6)$, the presence of a psychiatric comorbidity $(\mathrm{OR}=5.6)$ and low SES $(\mathrm{OR}=2.3)$ were associated with reduced response to methylphenidate treatment. Logistic regression analysis is shown in Table 5.

\section{DISCUSSION}

In this naturalistic study, we explored the relationship between two SNPs, ADRA2A rs1800544 and COMT rs4680, and ADHD phenotype, including ADHD subtype, treatment resistance, and psychiatric symptom severity.

There was no significant difference in the frequency of the

Table 2. Polymorphism genotypes in patients and normal controls

\begin{tabular}{ccccc}
\hline \multicolumn{4}{c}{ Genotype distribution, N (\%) } & $\chi^{2}$ \\
\hline rs4680 & GG & GA & AA & \\
Patients & $32(26.4)$ & $58(47.9)$ & $31(25.6)$ & $3.941^{*}$ \\
Controls & $39(38.2)$ & $44(43.1)$ & $19(18.6)$ & \\
rs1800544 & CC & GC & GG & \\
Patients & $66(54.5)$ & $47(38.8)$ & $8(6.6)$ & $4.261^{*}$ \\
Controls & $42(41.2)$ & $49(48)$ & $11(10.8)$ & \\
\hline
\end{tabular}

*not statistically significant

Table 3. Distribution of genotypes according to ADHD subtypes

\begin{tabular}{ccccc}
\hline \multicolumn{4}{c}{ Genotype distribution, N (\%) } & $\chi^{2}$ \\
\hline rs4680 & GG & GA & AA & \\
Combined & $25(26)$ & $42(43.8)$ & $29(30.2)$ & $5.544^{*}$ \\
Inattentive & $7(28)$ & $16(64)$ & $2(8)$ & \\
rs1800544 & CC & GC & GG & \\
Combined & $49(51)$ & $40(41.7)$ & $7(7.3)$ & $2.325^{*}$ \\
Inattentive & $17(68)$ & $7(28)$ & $1(4)$ & \\
*not statistically significant. ADHD: attention deficit hyperactivity \\
disorder
\end{tabular}

Table 4. Distribution of genotypes according to treatment response

\begin{tabular}{cccc}
\hline & \multicolumn{2}{c}{ Genotype distribution, N (\%) } & \multirow{2}{*}{$\chi^{2}$} \\
\cline { 2 - 3 } rs4680 & Responders & Non-responders & \\
GG & $22(75.9)$ & $7(24.1)$ & $2.757^{*}$ \\
GA & $32(59.3)$ & $22(40.7)$ & \\
AA & $18(72)$ & $7(28)$ & \\
rs1800544 & & & \\
CC & $42(67.7)$ & $20(32.3)$ & $3.424^{*}$ \\
GC & $27(71.1)$ & $11(28.9)$ & \\
GG & $3(37.5)$ & $5(62.5)$ & \\
\hline
\end{tabular}

*not statistically significant 
Table 5. Multiple logistic regression analysis

\begin{tabular}{|c|c|c|c|c|}
\hline \multirow{2}{*}{ Clinical parameters } & \multicolumn{2}{|c|}{ Confidence interval (95\%) } & \multirow{2}{*}{$\mathrm{p}$} & \multirow{2}{*}{ Odds ratio } \\
\hline & Minimum & Maximum & & \\
\hline rs1800544 GC & 0.352 & 2.469 & 0.887 & 0.932 \\
\hline rs1800544 GG & 1.043 & 30.641 & 0.045 & 5.655 \\
\hline Low Socioeconomic Status & 0.883 & 6.287 & 0.087 & 2.356 \\
\hline Psychiatric Comorbidity & 2.13 & 14.951 & 0.000 & 5.644 \\
\hline
\end{tabular}

two genotypes between the patient and the control groups. Although previous studies have shown that these polymorphisms were more common in the ADHD patient group compared to the general population, ${ }^{8,36}$ other reports have indicated no difference in SNP distribution. ${ }^{13,37}$ These results may be attributable to the multi-genic nature of ADHD. These polymorphisms may play a relatively small role as modifiers of ADHD etiology that are difficult to detect in small study groups. While the distribution of rs4680 genotypes in the present study was similar to previously reported distributions, ${ }^{8}$ this was not the case for rs $1800544.4^{20,36,38}$ This ADRA2A polymorphism occurred at a similar rate in both patient and control groups. This may be attributable to ethnic differences between the study groups.

In the present study, there was no association between high symptom severity, low clinical functionality and COMT polymorphism; as in some of the prior studies. ${ }^{11-13}$ Only the rs4686 haplotype of COMT SNP was evaluated in this study and it was therefore not possible for us to estimate the effects of other haplotype on ADHD risk. Other evidence suggests that COMT haplotypes may lead to changes in enzyme activity. ${ }^{39,40}$ Consequently, additional studies including other haplotypes of COMT must be carried out to evaluate the possible roles of COMT variations in ADHD etiology.

We did not observe significant differences in genotype distribution according to ADHD subtype. However, the methionine allele rs 4680 was more common in the combined subtype patient group, although this observation was not statistically significant. Contradicting studies investigating relationships between SNPs and ADHD subtypes have been reported in literature. While, the presence of the the valine allele at rs4680 in COMT has been associated with aggression, and indirectly with combined subtype in some studies, ${ }^{41,42}$ other reports indicate increased frequency of the methionine allele among patients with inattentive subtype $\mathrm{ADHD}^{43}$ and executive function defects. Executive functions can be directly impaired by valine allele, which results in high enzyme activity and low dopaminergic prefrontal status. ${ }^{13}$ Executive functions can also be augmented by the methionine allele, which causes low enzyme activity. ${ }^{44}$ Executive functions are not only relevant to attention, organization, and planning, but also impulsivity. This may account for the higher frequency of the me- thionine allele in the combined $\mathrm{ADHD}$ subtype group in the present study.

Although, we observed no relationship between rs1800544 frequency and predominantly inattentive subtype ADHD, there are examples of such cases in the literature. ${ }^{17,38}$ However, the presence of the $\mathrm{G}$ allele at rs 1800544 was associated with the learning problems CPRS sub-scale score and attention deficiency CTRS sub-scale score in the present study. Similar findings have been reported using alternate ADHD symptom scales..$^{20,38,45}$ On the contrary, Wang et al. ${ }^{46}$ found no relation between rs1800544 and ADHD symptoms. In our study, we found no association between COMT genotype and CPRS or CTRS sub-scales, as has been reported by Tahir et al. ${ }^{11}$ and challenged by other reports in the literature. ${ }^{41,42}$ As a result, the association of rs1800544 with CPRS and CTRS sub-scale scores implies that phenotypic discrimination by ADRA2A polymorphisms may be important. However, current ADHD subtypes may be inadequate to provide enough homogeneity for reliable phenotyping of ADHD. Hence, future genetic studies for these polymorphisms together with phenotyping on the basis of symptoms may provide more specific evidence.

In the present study, we found no association between rs4680 (COMT) and the presence of other psychiatric comorbidities, in contrast to the findings of other studies. ${ }^{41,43}$ In addition, we found no correlation between low SES and rs4680 frequency. This may be due to a selection bias resulting from the conduct of the study at a tertiary medical center with few patients of low SES (9.1\%). The largest proportion of participants were classified in the middle SES group (48.8\%). rs4680 was not associated with low familial functionality in this study. This may occur as a result of consistently low familial functionality throughout the study group. To our knowledge, this is the first study to explore the relationship between these polymorphisms and familial functionality in Turkish ADHD patients.

COMT polymorphism was not associated with treatment response in the univariate analysis, similar to prior studies. ${ }^{11,47,48}$ However, the valine allele for rs4680 (COMT) was more frequent among treatment responders relative to prior reports. ${ }^{8,13}$ In accordance with the results of Solanto et al. ${ }^{49}$ ADHD subtype was not associated with treatment response. However, this finding conflicts with reported differences in 
treatment response associated with ADHD subtype. ${ }^{50,51}$ In multiple regression analysis, low SES and the presence of psychiatric co-morbidities were associated with poor treatment response. Other studies have reported similar conclusions. ${ }^{50,52}$ This association may be attributable to poor adherence to treatment in low SES groups and the complexity of treatment procedures caused by psychiatric co-morbidities. Surprisingly, the GG genotype in rs1800544 was associated with poor treatment response in the present study. This is in opposition to previous studies, which have found that this allele is associated with improved treatment response. ${ }^{17,18,36}$ Contini et al. ${ }^{53}$ reported no difference in methylphenidate treatment response between ADRA2A G and C allele carriers. Differences in the ethnicity and heterogeneity of the study groups evaluated in the various reports may account for these apparent discrepancies.

The present study may be limited as a result of the exclusive inclusion of patients from a tertiary medical center. Consequently, these results may be difficult to generalize for the wider population. The naturalistic study design and the loss of 13 patients during the assessment procedure also limited the data collection. However, the patients were assessed using multiple clinical scales, neuropsychological tests, and co-morbidities in an effort to generate homogenous study groups. The control group included a significant number of subjects selected from a gender-matched population sample.

As a result, our study data indicates that $A D R A 2 A$ (rs1800544) SNP, low socioeconomic status, and the presence of psychiatric co-morbidities are associated with increased risk of poor methylphenidate response in ADHD. Drug free treatment plans including psychosocial interventions may be more suitable for patients with these risk factors. Our data regarding ADRA2A polymorphism is among the few $\mathrm{ADHD}$ polymorphism studies conducted in Turkish population. The incorporation of phenotyping in ADHD treatment may be premature, and as a result, more studies regarding genetic polymorphisms associated with ADHD are necessary to advance this field.

\section{Acknowledgments}

This study was supported by the Scientific and Technological Research Council of Turkey (TUBITAK) (project no: 112S378) and the Hacettepe University Scientific Research Projects Coordination Unit (project no: 012 D07 101 003).

We would like to thank Gizem Sakarya (psychologist) and Serkan Kabacam (biologist) for their assistance in this research.

\section{REFERENCES}

1. Polanczyk G, de Lima MS, Horta BL, Biederman J, Rohde LA. The worldwide prevalence of ADHD: a systematic review and metaregression analysis. Am J Psychiatry 2007;164:942-948.

2. Sonuga-Barke EJ, Halperin JM. Developmental phenotypes and causal pathways in attention deficit/hyperactivity disorder: potential targets for early intervention? J Child Psychol Psychiatry 2010;51:368-389.

3. Faraone SV, Perlis RH, Doyle AE, Smoller JW, Goralnick JJ, Holmgren MA, et al. Molecular genetics of attention-deficit/hyperactivity disorder. Biol Psychiatry 2005;57:1313-1323.

4. Pliszka SR. The neuropsychopharmacology of attention-deficit/hyperactivity disorder. Biol Psychiatry 2005;57:1385-1390.

5. Sonuga-Barke EJ. Causal models of attention-deficit/hyperactivity disorder: from common simple deficits to multiple developmental pathways. Biol Psychiatry 2005;57:1231-1238.

6. Lachman HM, Papolos DF, Saito T, Yu YM, Szumlanski CL, Weinshilboum RM. Human catechol-o-methyltransferase pharmacogenetics: description of a functional polymorphism and its potential application to neuropsychiatric disorders. Pharmacogenetics 1996;6:243-250.

7. Bellgrove MA, Domschke K, Hawi Z, Kirley A, Mullins C, Robertson $\mathrm{IH}$, et al. The methionine allele of the COMT polymorphism impairs prefrontal cognition in children and adolescents with ADHD. Exp Brain Res 2005;163:352-360.

8. Kereszturi E, Tarnok Z, Bognar E, Lakatos K, Farkas L, Gadoros J, et al. Catechol-o-methyltransferase val158met polymorphism is associated with methylphenidate response in ADHD children. Am J Med Genet B Neuropsychiatr Genet 2008;147B:1431-1435.

9. Barr CL, Wigg K, Malone M, Schachar R, Tannock R, Roberts W, et al. Linkage study of catechol-o-methyltransferase and attention-deficit hyperactivity disorder. Am J Med Genet 1999;88:710-713.

10. Hawi Z, Millar N, Daly G, Fitzgerald M, Gill M. No association between catechol-o-methyltransferase (COMT) gene polymorphism and attention deficit hyperactivity disorder (ADHD) in an irish sample. Am J Med Genet 2000;96:282-284.

11. Tahir E, Curran S, Yazgan Y, Ozbay F, Cirakoglu B, Asherson PJ. No association between low- and high-activity catecholamine-methyltransferase (COMT) and attention deficit hyperactivity disorder (ADHD) in a sample of turkish children. Am J Med Genet 2000;96:285288.

12. Yatsuga C, Toyohisa D, Fujisawa TX, Nishitani S, Shinohara K, Matsuura N, et al. No association between catechol-o-methyltransferase (COMT) genotype and attention deficit hyperactivity disorder (ADHD) in japanese children. Brain Dev 2014;36:620-625.

13. Cheuk DK, Wong V. Meta-analysis of association between a catecholo-methyltransferase gene polymorphism and attention deficit hyperactivity disorder. Behav Genet 2006;36:651-659.

14. Arnsten AF. Stimulants: therapeutic actions in ADHD. Neuropsychopharmacology 2006;31:2376-2383.

15. Arnsten AF, Steere JC, Hunt RD. The contribution of alpha 2-noradrenergic mechanisms of prefrontal cortical cognitive function. Potential significance for attention-deficit hyperactivity disorder. Arch Gen Psychiatry 1996;53:448-455.

16. Greene CM, Bellgrove MA, Gill M, Robertson IH. Noradrenergic genotype predicts lapses in sustained attention. Neuropsychologia 2009; 47:591-594.

17. da Silva TL, Pianca TG, Roman T, Hutz MH, Faraone SV, Schmitz M, et al. Adrenergic alpha2A receptor gene and response to methylphenidate in attention-deficit/hyperactivity disorder-predominantly inattentive type. J Neural Transm (Vienna) 2008;115:341-345.

18. Polanczyk G, Zeni C, Genro JP, Guimarães AP, Roman T, Hutz MH, et al. Association of the adrenergic alpha2A receptor gene with methylphenidate improvement of inattentive symptoms in children and adolescents with attention-deficit/hyperactivity disorder. Arch Gen Psychiatry 2007;64:218-224.

19. Deupree JD, Smith SD, Kratochvil CJ, Bohac D, Ellis CR, Polaha J, et al. Possible involvement of alpha-2A adrenergic receptors in attention deficit hyperactivity disorder: radioligand binding and polymorphism studies. Am J Med Genet B Neuropsychiatr Genet 2006;141B:877-884.

20. Schmitz M, Denardin D, Silva TL, Pianca T, Roman T, Hutz MH, et al. Association between alpha-2A-adrenergic receptor gene and ADHD 
inattentive type. Biol Psychiatry 2006;60:1028-1033.

21. Kaufman J, Birmaher B, Brent D, Rao U, Flynn C, Moreci P, et al. Schedule for affective disorders and schizophrenia for school-age childrenpresent and lifetime version (K-SADS-PL): initial reliability and validity data. J Am Acad Child Adolesc Psychiatry 1997;36:980-988.

22. Wechsler D. WISC-IV Technical and Interpretive Manual. San Antonio, TX: Psychological Corporation; 2003.

23. Wechsler D. WISC-R Manual for the Wechsler Intelligence Scale for Children-Revised. New York: Psychological Corporation; 1974.

24. Turgut S, Erden G, Karakas S. The profiles of Specific Learning Disability (SLD), attention deficit hyperactivity disorder comorbid with SLD and control group through the SLD battery. Turk J Child Adolesc Ment Health 2010;17:13-26.

25. Pliszka S; AACAP Work Group on Quality Issues. Practice parameter for the assessment and treatment of children and adolescents with attention-deficit/hyperactivity disorder. J Am Acad Child Adolesc Psychiatry 2007;46:894-921.

26. Conners CK, Barkley RA. Rating scales and checklists for child psychopharmacology. Psychopharmacol Bull 1985;21:809-843.

27. Reitan RM. Validity of the trail making test as an indicator of organic brain damage. Percept Mot Skills 1958;8:271-276.

28. Greenberg LM, Waldman ID. Developmental normative data on the test of variables of attention (T.O.V.A.). J Child Psychol Psychiatry 1993;34:1019-1030.

29. Ward MF, Wender PH, Reimherr FW. The Wender Utah Rating Scale: an aid in the retrospective diagnosis of childhood attention deficit hyperactivity disorder. Am J Psychiatry 1993;150:885-890.

30. Epstein NB, Baldwin LM, Bishop DS. The McMaster family assessment device. J Marital Fam Ther 1983;9:171-180.

31. Polanczyk G, Faraone SV, Bau CH, Victor MM, Becker K, Pelz R, et al. The impact of individual and methodological factors in the variability of response to methylphenidate in ADHD pharmacogenetic studies from four different continents. Am J Med Genet B Neuropsychiatr Genet 2008;147B:1419-1424.

32. Handen BL, Johnson CR, Lubetsky M. Efficacy of methylphenidate among children with autism and symptoms of attention-deficit hyperactivity disorder. J Autism Dev Disord 2000;30:245-255.

33. Hale JB, Reddy LA, Semrud-Clikeman M, Hain LA, Whitaker J, Morley J, et al. Executive impairment determines ADHD medication response: implications for academic achievement. J Learn Disabil 2011; 44:196-212.

34. Yuan X, Zhou G, Zhai Y, Xie W, Cui Y, Cao J, et al. Lack of association between the functional polymorphisms in the estrogen-metabolizing genes and risk for hepatocellular carcinoma. Cancer Epidemiol Biomarkers Prev 2008;17:3621-3627.

35. Lario S, Calls J, Cases A, Oriola J, Torras A, Rivera F. Mspi identifies a biallelic polymorphism in the promoter region of the alpha $2 \mathrm{~A}$-adrenergic receptor gene. Clin Genet 1997;51:129-130.

36. Cheon KA, Cho DY, Koo MS, Song DH, Namkoong K. Association between homozygosity of a $\mathrm{G}$ allele of the alpha-2a-adrenergic receptor gene and methylphenidate response in Korean children and adolescents with attention-deficit/hyperactivity disorder. Biol Psychiatry 2009;65:564-570.

37. Shiffrin ND, Gruber J, Glatt SJ, Faraone SV. No association between Mspi allele of the ADRA2A polymorphism and ADHD: meta-analysis of family-based studies. Psychiatr Genet 2013;23:174-175.

38. Roman T, Polanczyk GV, Zeni C, Genro JP, Rohde LA, Hutz MH. Further evidence of the involvement of alpha-2A-adrenergic receptor gene (ADRA2A) in inattentive dimensional scores of attention-deficit/hyperactivity disorder. Mol Psychiatry 2006;11:8-10.
39. Nackley AG, Shabalina SA, Tchivileva IE, Satterfield K, Korchynskyi O, Makarov SS, et al. Human catechol-O-methyltransferase haplotypes modulate protein expression by altering mRNA secondary structure. Science 2006;314:1930-1933.

40. Halleland H, Lundervold AJ, Halmoy A, Haavik J, Johansson S. Association between catechol O-methyltransferase (COMT) haplotypes and severity of hyperactivity symptoms in adults. Am J Med Genet B Neuropsychiatr Genet 2009;150B:403-410.

41. Caspi A, Langley K, Milne B, Moffitt TE, O’Donovan M, Owen MJ, et al. A replicated molecular genetic basis for subtyping antisocial behavior in children with attention-deficit/hyperactivity disorder. Arch Gen Psychiatry 2008;65:203-210.

42. Monuteaux MC, Biederman J, Doyle AE, Mick E, Faraone SV. Genetic risk for conduct disorder symptom subtypes in an ADHD sample: specificity to aggressive symptoms. J Am Acad Child Adolesc Psychiatry 2009;48:757-764.

43. Qian QJ, Liu J, Wang YF, Yang L, Guan LL, Faraone SV. Attention deficit hyperactivity disorder comorbid oppositional defiant disorder and its predominately inattentive type: evidence for an association with COMT but not MAOA in a Chinese sample. Behav Brain Funct 2009; 5:8.

44. Levy F. What do dopamine transporter and catechol-o-methyltransferase tell us about attention deficit-hyperactivity disorder? Pharmacogenomic implications. Aust N Z J Psychiatry 2007;41:10-16.

45. Ogdie MN, Fisher SE, Yang M, Ishii J, Francks C, Loo SK, et al. Attention deficit hyperactivity disorder: Fine mapping supports linkage to 5p13, 6q12, 16p13, and 17p11. Am J Hum Genet 2004;75:661-668.

46. Wang B, Wang Y, Zhou R, Li J, Qian Q, Yang L, et al. Possible association of the alpha-2A adrenergic receptor gene (ADRA2A) with symptoms of attention-deficit/hyperactivity disorder. Am J Med Genet B Neuropsychiatr Genet 2006;141B:130-134.

47. Contini V, Victor MM, Bertuzzi GP, Salgado CA, Picon FA, Grevet $\mathrm{EH}$, et al. No significant association between genetic variants in 7 candidate genes and response to methylphenidate treatment in adult patients with ADHD. J Clin Psychopharmacol 2012;32:820-823.

48. Froehlich TE, Epstein JN, Nick TG, Melguizo Castro MS, Stein MA, et al. Pharmacogenetic predictors of methylphenidate dose-response in attention-deficit/hyperactivity disorder. J Am Acad Child Adolesc Psychiatry 2011;50:1129-1139.

49. Solanto M, Newcorn J, Vail L, Gilbert S, Ivanov I, Lara R. Stimulant drug response in the predominantly inattentive and combined subtypes of attention-deficit/hyperactivity disorder. J Child Adolesc Psychopharmacol 2009;19:663-671.

50. Chazan R, Borowski C, Pianca T, Ludwig H, Rohde LA, Polanczyk G. Do phenotypic characteristics, parental psychopathology, family functioning, and environmental stressors have a role in the response to methylphenidate in children with attention-deficit/hyperactivity disorder? A naturalistic study from a developing country. J Clin Psychopharmacol 2011;31:309-317.

51. Gorman EB, Klorman R, Thatcher JE, Borgstedt AD. Effects of methylphenidate on subtypes of attention-deficit/hyperactivity disorder. J Am Acad Child Adolesc Psychiatry 2006;45:808-816.

52. Ghuman JK, Arnold LE, Anthony BJ. Psychopharmacological and other treatments in preschool children with attention-deficit/hyperactivity disorder: current evidence and practice. J Child Adolesc Psychopharmacol 2008;18:413-447.

53. Contini V, Victor MM, Cerqueira CC, Polina ER, Grevet EH, Salgado $\mathrm{CA}$, et al. Adrenergic $\alpha 2 \mathrm{~A}$ receptor gene is not associated with methylphenidate response in adults with ADHD. Eur Arch Psychiatry Clin Neurosci 2011;261:205-211. 